\title{
Influence of atherosclerosis on the molecular expression of the TRPC1/BK signal complex in the aortic smooth muscles of mice
}

\author{
LIAN-FA WANG $^{1 *}$, DONG-YUN LING ${ }^{2 *}$, MENG-XUN HUANG $^{1}$, LI-WEI TAO ${ }^{3}$, \\ QUAN-XIU TONG ${ }^{1}$, YONG HOU ${ }^{1}$, HUA LI $^{1}$, ZHEN CHEN $^{1}$, BANG-ZHU ZHANG ${ }^{1}$, \\ HONG-TAO LU ${ }^{1}$, YUN-FEI WANG ${ }^{1}$ and XIAN-GE ZHANG ${ }^{4}$
}

\author{
${ }^{1}$ Department of Cardiology, The 901st Hospital of Joint Logistics Support Force of PLA, Hefei, Anhui 230031; \\ ${ }^{2}$ Department of Cardiology, The Second People's Hospital of Hefei City, Hefei, Anhui 230011; \\ ${ }^{3}$ Department of Cardiothoracic Surgery, The Second People's Hospital of Fuyang City, Fuyang, \\ Anhui 236000, P.R. China; ${ }^{4}$ Institute of Public Health and Nursing Research, Department \\ of Healthcare Management, University of Bremen, 28359 Bremen, Germany
}

Received March 3, 2020; Accepted July 8, 2021

DOI: $10.3892 / \mathrm{etm} .2021 .10926$

\begin{abstract}
Atherosclerosis (AS) is one a disease that seriously endangers human health. Previous studies have demonstrated that transient receptor potential channel-1 (TRPC1)/large conductance $\mathrm{Ca}^{2+}$ activated $\mathrm{K}^{+}$channel (BK) signal complex is widely distributed in arteries. Therefore, it was hypothesized that TRPC1-BK signal complex may be a new target for the treatment of AS-related diseases. Apolipoprotein $\mathrm{E}^{-/-}\left(\mathrm{ApoE}^{-/}\right)$ mice were used to establish an atherosclerotic animal model in the present study, and the association between AS and the TRPC1-BK signal complex was examined. The present study aimed to compare the differences in the expression levels of mRNAs and proteins of the TRPC1-BK signal complex expressed in the aortic vascular smooth muscle tissue, between mice with AS and control mice. There were 10 mice in each group. Reverse transcription PCR, western blotting and immunohistochemistry were used to detect the differences in the mRNA and protein expression levels of TRPC1, $\mathrm{BK} \alpha$ (the $\alpha$ subunit of $\mathrm{BK}$ ) and $\mathrm{BK} \beta_{1}$ (the $\beta_{1}$ subunit of $\mathrm{BK}$ ). The mRNA expression level of TRPC1 in AS model mice was significantly higher compared with that in the control group $(\mathrm{P}<0.05)$. However, the mRNA expression levels of $\mathrm{BK} \alpha$ and $\mathrm{BK} \beta_{1}$ were lower compared with those in the controls
\end{abstract}

Correspondence to: Professor Lian-Fa Wang, Department of Cardiology, The 901st Hospital of Joint Logistics Support Force of PLA, 424 Changjiang West Road, Hefei, Anhui 230031, P.R. China E-mail: cnlianfawang@126.com

*Contributed equally

Key words: large-conductance calcium-activated potassium channels, atherosclerosis, myocytes, smooth muscle, gene knockout techniques. (both $\mathrm{P}<0.01)$. The mice in the $\mathrm{ApoE}^{-/-}$group successfully developed AS. In this group, the protein expression level of TRPC1 was significantly higher than that in the control group $(\mathrm{P}<0.01)$, while the protein expression levels of $\mathrm{BK} \alpha$ and $\mathrm{BK} \beta_{1}$ were lower compared with those in the control group $(\mathrm{P}<0.01$ and $\mathrm{P}<0.05$, respectively). Collectively, it was identified that the protein and mRNA expression levels of the TRPC1/BK signal complex in the aortic vascular smooth muscle tissue could be influenced by the development of AS in mice. Hence, the TRPC1/BK signal complex may be a potential therapeutic target for the prevention and treatment of AS-related complications in the future.

\section{Introduction}

Atherosclerosis (AS) is an inflammatory disease marked by hyperplastic lesions that are formed in the arterial intima, such as coronary artery, carotid artery and peripheral artery (1). It is characterized by the thickening, hardening, elasticity loss and reduction of lumen size of the arterial wall. AS mainly occurs in large and medium-sized arteries and internal arterial branches. While it is presumed that AS is a disease caused by multiple factors, its etiology remains unknown. Multiple risk factors have been identified, such as dyslipidemia, hypertension, smoking, diabetes, abnormal glucose tolerance, age, sex and genetic factors (1). Moreover, AS is the pathophysiological precursor for the development of ischemic cardio-cerebrovascular disease (2). With the improvement in living standards and due to lifestyle-related changes, ischemic cardio-cerebrovascular disease has become a serious threat to human health (3). AS treatment includes surgery and drug therapy. The purpose of the surgical treatments, such as stenting and bypass surgery, is to restore the blood supply by correcting the stenosis or occlusion of the arteries, especially in the coronary and renal arteries, as well as the arteries of the limbs. Furthermore, drug therapy mainly aims to lower blood lipid levels to prevent or inhibit the formation and progression 
of AS plaques (4). Hence, research on the pathogenesis of AS and disease prevention strategies has become a pressing issue. The efforts of numerous researchers are directed at present towards investigating the prevention and control of the pathogenesis and progression of AS and its related diseases.

Transient receptor potential channel-1 (TRPC1) is a $\mathrm{Ca}^{2+}$ channel present on the cell membrane, especially in vascular smooth muscle cells (VSMCs). As a cell receptor, TRPC1 can receive signals and stimuli from both inside and outside the cell (5). The channel is regulated by intracellular $\mathrm{Ca}^{2+}$ concentration. When $\mathrm{Ca}^{2+}$ ions are depleted from the sarcoplasmic reticulum, TRPC1 opens, allowing for $\mathrm{Ca}^{2+}$ inflow, resulting in depolarization and contraction of the cells, which in turn causes contraction of the blood vessels (6). The large conductance $\mathrm{Ca}^{2+}$-activated $\mathrm{K}^{+}$channel (BK) is widely distributed in the cell membranes of vascular smooth muscles. Each BK comprises four $\alpha$ subunits, the main function of which is to regulate the $\beta$ subunit $1\left(\mathrm{BK} \beta_{1}\right)(7)$. When the intracellular $\mathrm{Ca}^{2+}$ concentration is increased, the BK pathway is activated and there is $\mathrm{K}^{+}$outflow, resulting in hyperpolarization. This in turn inhibits the opening of the $\mathrm{Ca}^{2+}$ channel and reduces the $\mathrm{Ca}^{2+}$ inflow, thereby causing cell depolarization (7). When the blood vessels are treated with BK-specific blockers in vitro, depolarization of the cell membrane of VSMCs occurs, leading to an increase in vascular tension, which shows that the BKs serve a critical role in regulating vascular smooth muscle tension.

TRPC1 can interact with transport and scaffolding proteins, such as $\beta$-tublin (8), ankyrin (9), caveolin (10), Homers (11), MX dynamin like GTPase 1 (12), ras homolog family member A (13), synaptosome associated protein 25 (13) and vesicle associated membrane protein 1 (14), which are responsible for vesicle transport, membrane fusion and cytoskeleton rearrangement process regulation. Moreover, TRPC1 participates in signal pathways with proteins such as inositol 1,4,5-trisphosphate receptor type 3 (15), calmodulin (16), $\mathrm{Gq} / 11$ (a member of $\mathrm{G}$ proteins) (17), phosphoinositide phospholipase $\mathrm{C} \gamma$ (18), plasma membrane calcium-transporting ATPase (19), sarcoplasmic/endoplasmic reticulum calcium ATPase (20) and stromal interaction molecule 1 (21) to regulate the physiological function of cells.

Previous studies have revealed that TRPC1 and BK form a signal complex on the surface of the VSMC membrane $(22,23)$. The TRPC1/BK signal complex regulates the changes in intracellular $\mathrm{Ca}^{2+}$ concentration in a stable physical and chemical environment to achieve steady vascular tension and regulate the blood flow (22). The cell membrane of normal smooth muscle cells possesses a large number of caveolae that are framed by caveolin 1. A variety of channels, receptors and regulatory proteins can be found in these caveolae $(24,25)$. TRPC1 in the caveolae interacts with numerous signal molecules or membrane proteins to form a complex and mediate signal transduction. The TRPC1 protein needs to be in the form of a signal complex to perform its physiological function $(22,24,25)$. TRPC1 is involved in the depolarization of the aortal VSMCs, and BK is involved in the repolarization of the arterial smooth muscle cells (22). The hyperpolarization of the TRPC1/BK signal complex can reduce the dopant-induced cell membrane depolarization and prevent excessive contraction of the arterial smooth muscle cells (22). Via $\mathrm{Ca}^{2+}$ signal transduction, TRPC1 and BK can regulate vasoconstriction and diastole. AS leads to a series of pathophysiological changes in the vessel wall and, therefore, the ion channels present on the vessel wall are also affected (22). Although there are a few reports on the involvement of the TRPC1/BK signal complex in the regulation of tension in the VSMCs, in-depth studies on the functional mechanisms of TRPC1/BK signaling in vascular disease, particularly atherosclerotic lesions, are lacking. Further research on the TRPC1/BK signal complex may provide a novel theoretical basis for the treatment of atherosclerotic disease and lead to the discovery of new treatments. Therefore, the present study investigated the expression of the TRPC1/BK signal complex in arterial tissue at the molecular level.

\section{Materials and methods}

Main reagents and equipment. The following were used in the present study: TRPC1 rabbit anti-mouse primary antibody (cat. no. NB100-98844; Novus Biologicals, LLC; western blotting dilution, 1:1,000; immunohistochemistry dilution, 1:1,000), BK $\alpha$ rabbit anti-mouse primary antibody (cat. no. NBP1-46701; Novus Biologicals, LLC; western blotting dilution, 1:1,000; immunohistochemistry dilution, 1:500) and $\mathrm{BK} \beta_{1}$ rabbit anti-mouse primary antibody (cat. no. NB300-535; Novus Biologicals, LLC; western blotting dilution, 1:1,000; immunohistochemistry dilution, 1:500); $\beta$-actin rabbit anti-mouse primary antibody (cat. no. 4970S; Cell Signaling Technology, Inc.; western blotting dilution, 1:1,000; immunohistochemistry dilution, 1:200); HRP-labeled goat anti-rabbit secondary antibody (cat. no. ZB-2301; OriGene Technologies, Inc.; dilution, 1:10,000); ECL kit (Thermo Fisher Scientific, Inc.); 3,3'-diaminobenzidine (DAB) kit (Beijing Golden Bridge Biotechnology Co., Ltd.); TRIzol ${ }^{\circledR}$ kit (Invitrogen; Thermo Fisher Scientific, Inc.); PCR two-step kit (Beijing Kangwei Century Biotechnology Co., Ltd.); electrophoresis instrument (Shanghai Tianneng Electronics); PCR gene amplification and PCR electrophoresis (Applied Biosystems; Thermo Fisher Scientific, Inc.); fluorescence and chemiluminescence imaging analysis system (Analytik Jena AG); light microscope (Olympus Corporation); paraffin tissue microtome (Beijing Century Science and Technology Co., Ltd.); color digital CCD camera (Nikon Corporation); Metamorph biological imaging software (version 1.12.2; Universal Imaging, Inc.).

Animal studies. For the animal experiments, 10 apolipoprotein $\mathrm{E}(\mathrm{ApoE})^{-/-}$mice (purchased from Beijing Huafukang Biotech Co., Ltd.) were used in the experimental group, and 10 wild-type C57BL/6J mice (purchased from the Experimental Animal Center of Anhui Medical University; Hefei, China) were included in the control group. These mice were 6-8 weeks old, were housed in the specific pathogen free experimental animal center (temperature, $23^{\circ} \mathrm{C}$; humidity, $67 \%$, light/dark cycle, 12/12 h) and had free access to autoclaved food and sterilized water. The mice in the experimental group were kept on a high-fat diet (17.9\% crude fat) to promote the formation of atherosclerotic plaques (26), while the mice in the control group were kept on normal feed for 10 weeks. 
Aortic tissue separation. The mice were anesthetized using an intraperitoneal injection of $0.5-1 \mathrm{ml} 4 \%$ pentobarbital ( $\sim 80 \mathrm{mg} / \mathrm{kg})$. The mice were fixed on the dissection table, their chest skin was cut along the median line and was blunt dissected on the left and right sides. The chest was opened to reveal the heart, and $\sim 0.5 \mathrm{~cm}$ section of the aorta was cut from the heart and carefully separated into the ascending aorta, aortic arch and thoracic aorta. Immediately after the artery was separated, the tissue was washed three times with saline and blotted to remove residual moisture.

Tissue sections. The dissected arterial tissue was immersed in $4 \%$ paraformaldehyde, fixed for $24 \mathrm{~h}$ at $4{ }^{\circ} \mathrm{C}$ and then embedded with paraffin. As the AS lesions are mainly found in the ascending aorta to the aortic arch part during the first occurrence (27), this region was sectioned at $3 \mu \mathrm{m}$ layer by layer and made transparent for H\&E staining (hematoxylin staining for $10 \mathrm{~min}$, then eosin staining for 5 min; room temperature). Sections were observed using a light microscope. In the film, obvious AS lesions were observed, thereby indicating the success in modeling AS in the $\mathrm{ApoE}^{-/}$mice.

Separation of vascular smooth muscle layer. Using the $\mathrm{ApoE}^{-/-}$mice in which AS were successfully established, the aorta was isolated using the same method as aforementioned. To observe the middle vascular smooth muscle layer, the vascular outer membrane was stripped off with ophthalmic tweezers and the endovascular layer was scrapped away using absorbent cotton. Finally, the middle smooth muscle layer was obtained for the subsequent experimental study, as described below.

mRNA detection. Reverse transcription PCR (RT-PCR) was performed as previously reported (28). Total RNA was extracted using TRIzol reagent (Thermo Fisher Scientific, Inc.) from VSMC tissue of the middle layer vessels. A universal RT-PCR detection kit from Beijing ComWin Biotech Co., Ltd. was used according to the manufacturer's instructions. Genes coding for TRPC1, BK $\alpha$ and $\mathrm{BK} \beta_{1}$ proteins were denoted as TRPC1, $\mathrm{K}^{+} \mathrm{Ca}^{2+}$-activated channel subfamily $\mathrm{M} \alpha 1$ (KCNMA1) and $\mathrm{K}^{+} \mathrm{Ca}^{2+}$-activated channel subfamily $M$ regulatory $\beta$ subunit 1 (KCNMB1). The following primers were used: TRPC1 sense, 5'-GCCGTAA GCCCACCTGTAA-3' and antisense, 5'-TTGTGAGCCA CCACTTTGAG-3'; KCNMA1 sense, 5'-CGGGGTCTTG CAGGCTAAT-3' and antisense, 5'-GGTCATCGTCATCGT CTTGGT-3'; KCNMB1 sense, 5'-CGGGGTCTTGCAGGC TAAT-3' and antisense, 5'-CGCCAAGATGGATAGGGA-3'; and GAPDH sense, 5'-GGAAGCTTGTCATCAACGGG-3' and antisense, 5-AGTGATGGCATGGACTGTGG-3'. These were designed using the mouse TRPC1, KCNMA1 and KCNMB1 sequences from PubMed GeneBank. GAPDH was used as the internal reference. The primers were synthesized by Sangon Biotech Co., Ltd. RT-PCR was performed using the Mastercycler personal (Eppendorf). Following RT and cDNA amplification, PCR was performed with the following thermocycling conditions: $94^{\circ} \mathrm{C}$ for $3 \mathrm{~min}$; 30 cycles of $94^{\circ} \mathrm{C}$ for $30 \mathrm{sec}, 55^{\circ} \mathrm{C}$ for $30 \mathrm{sec}, 72^{\circ} \mathrm{C}$ for $2 \mathrm{~min}$; and $72^{\circ} \mathrm{C}$ for $5 \mathrm{~min}$. The products were analyzed via electrophoresis on $2 \%$ agarose gel, and ethidium bromide was used for visualization. Next, images were captured using a radiography gel imaging system (ProteinSimple). Densitometry of each band was performed using TotalLab Quant (version 12; TotalLab Ltd.).

Western blot analysis. The smooth muscle cell layers obtained by peeling off the adventitial layers with forceps were homogenized and after a round of high speed $\left(12,000 \mathrm{x} \mathrm{g} ; 4^{\circ} \mathrm{C} ; 5 \mathrm{~min}\right)$ centrifugation, the supernatant was obtained and the total protein concentration was measured by detecting the A562 absorbance value. RIPA buffer (cat. no. P0013B; Beyotime Institute of Biotechnology) was used for protein extraction. The BCA method was used for protein determination. The samples $(75 \mu \mathrm{g}$ protein/lane) were subjected to $10 \%$ SDS-PAGE and the proteins were transferred onto a PVDF membrane, which was blocked using 5\% skimmed milk at room temperature for $2 \mathrm{~h}$. After incubating with primary antibodies (TRPC $1, \mathrm{BK} \alpha, \mathrm{BK} \beta_{1}$ or $\beta$-actin rabbit anti-mouse primary antibodies) on a shaker at $4^{\circ} \mathrm{C}$ overnight, followed by incubation with secondary antibody (HRP-labeled goat anti-rabbit secondary antibody) for $1 \mathrm{~h}$ at room temperature, the proteins were detected on an X-ray film using an ECL kit (Thermo Fisher Scientific, Inc.). Densitometry was performed via ImageJ software (v1.8.0.112; National Institutes of Health).

Immunohistochemistry. Samples obtained from the operation were fixed at $4^{\circ} \mathrm{C}$ in $4 \%$ paraformaldehyde for $24 \mathrm{~h}$ and then embedded in paraffin. Paraffin-embedded samples were sectioned into 5-mm-thick sections and the slides were incubated at $56^{\circ} \mathrm{C}$ for $4 \mathrm{~h}$. The sections from paraffin-embedded aortic smooth muscle layers were de-paraffinized and hydrated. Antigen retrieval was carried out by adding $10 \mathrm{mmol} / \mathrm{l}$ sodium citrate solution ( $\mathrm{pH} 6.0 \pm 0.1$ ) and heating in the microwave for $10 \mathrm{~min}$. Next, $3 \%$ aqueous hydrogen peroxide solution added to the sections for $10 \mathrm{~min}$ at room temperature for reducing the activity of endogenous peroxidase. The sections were incubated overnight at $4^{\circ} \mathrm{C}$ with the following primary monoclonal antibodies: TRPC1 (Alomone Labs), BK $\alpha$ (Alomone Labs) and $\mathrm{BK} \beta_{1}$ (Alomone Labs). Next, the sections were incubated with appropriate HRP-conjugated secondary antibodies (OriGene Technologies, Inc.) for $30 \mathrm{~min}$ at $37^{\circ} \mathrm{C}$. Then, DAB was added to the sections for coloration for $3 \mathrm{~min}$ at room temperature and terminated by adding double distilled water. Finally, hematoxylin counterstaining was performed for $4 \mathrm{~min}$ at room temperature. For negative controls, the primary antibody was omitted. Subsequently, under light microscope (magnification, x400), a Nikon color digital CCD camera was used to capture the images of each group of immunohistochemical staining sections.

Statistical analysis. Data are presented as the mean \pm SEM. Statistical differences were examined using one-way ANOVA followed by the Newman-Keuls post hoc test and SigmaStat 4.0 software (Systat Software, Inc.). All experiments, including RT-PCR, western blotting and animal tissue staining, were repeated independently on samples from at least 3 mice, yielding similar results. $\mathrm{P}<0.05$ was considered to indicate a statistically significant difference. Graphs were plotted using GraphPad Prism 6.01 (GraphPad Software, Inc.). 


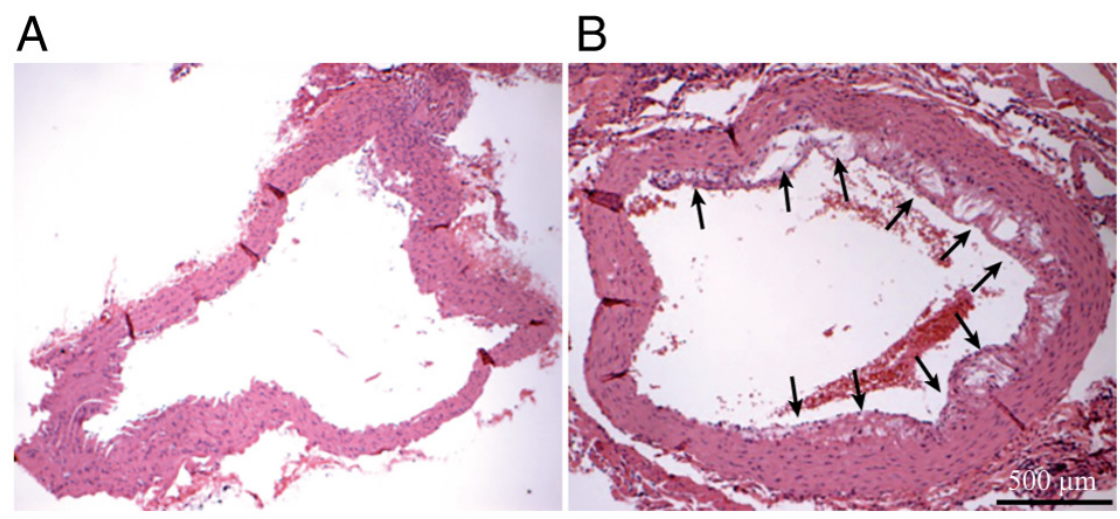

Figure 1. Optical microscopy H\&E staining was used to detect AS formation in the aortic tissue of the two groups (n=10). (A) Aortic lumen of mice in the control group. (B) Aortic lumen of the experimental apolipoprotein $\mathrm{E}^{-/-}$group of mice, with thickening of the vessel wall and cholesterol crystal deposits under the intima. Arrows refer to the atherosclerotic lesions, the general optical microscope (magnification, x100). AS, atherosclerosis.

A

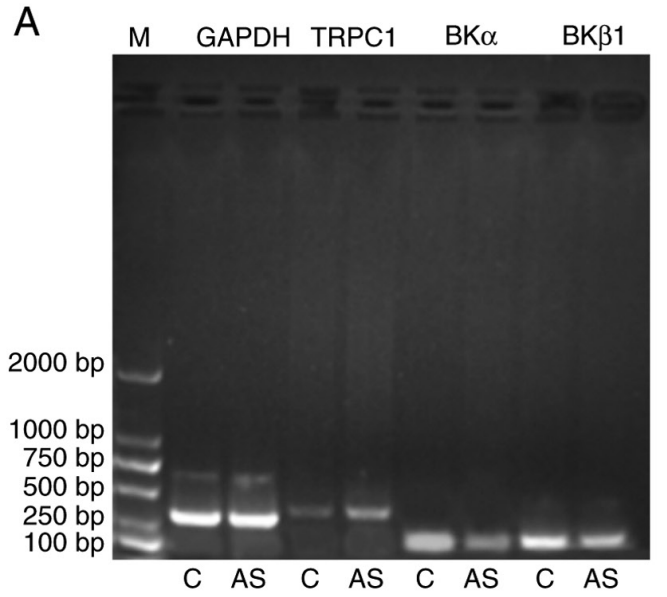

B

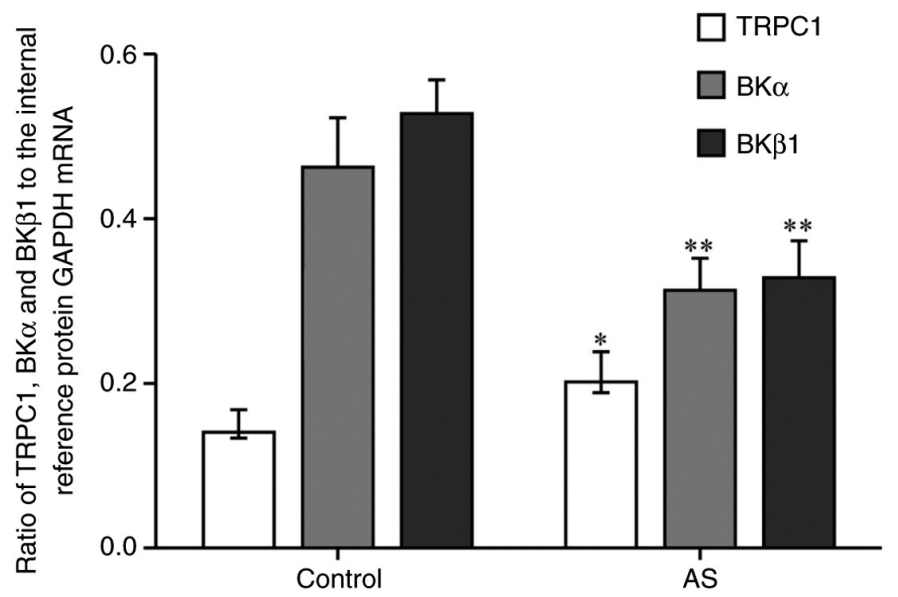

Figure 2. Reverse transcription PCR was used to detect the different mRNA expression levels in the aortic smooth muscle of the two groups (n=10). (A) The RNA band of TRPC1 in the AS group was brighter than that in the control group, whereas RNA bands of BK $\alpha$ and BK $\beta_{1}$ in the AS group were darker than those in the control group. ' $\mathrm{C}$ ' indicates the control group, ' $\mathrm{M}$ ' indicates the marker. (B) Histogram showing that there are statistical differences between the AS group and the control group RNA. ${ }^{*} \mathrm{P}<0.05,{ }^{* *} \mathrm{P}<0.01$ vs. respective control group. AS, atherosclerosis; TRPC1, transient receptor potential channel-1; $\mathrm{BK}$, large conductance $\mathrm{Ca}^{2+}$ activated $\mathrm{K}^{+}$channel.

\section{Results}

Atherosclerotic lesions. After H\&E staining, the aortic tissue sections from the $\mathrm{ApoE}^{-/-}$mice were observed under an Olympus microscope (BX 53) (Fig. 1) and atherosclerotic lesions (shown by arrows in Fig. 1B) were detected, suggesting that the AS model was successfully established. The aortic sections collected from the mice in the control group did not have any atherosclerotic lesions.

TRPC1, BK $\alpha$ and $B K \beta_{1} m R N A$ expression. Compared with the control group, the mRNA expression level of TRPC1 in aortic vascular smooth muscle of AS group was increased significantly $(\mathrm{P}<0.05$; Fig. 2), whereas the mRNA expression levels of $\mathrm{BK} \alpha$ and $\mathrm{BK} \beta_{1}$ were decreased $(\mathrm{P}<0.01)$.

TRPC1, $B K \alpha$ and $B K \beta_{1}$ protein expression. In Fig. 3, the grayish-yellow regions show the proteins of vascular smooth muscle tissue stained by the immunohistochemical reaction, and the blue parts show the nucleus. Compared with the control group, the protein expression level of TRPC1 in the mice in the AS group was increased $(\mathrm{P}<0.01)$, whereas the expression level of $\mathrm{BK} \alpha$ protein was decreased $(\mathrm{P}<0.01)$, as seen in the slides under the same background light intensity. Moreover, $\mathrm{BK} \beta_{1}$ protein expression was also decreased $(\mathrm{P}<0.05)$. The increase and decrease of these protein expression levels were consistent with the results of the western blotting (Fig. 4).

TRPC1, BK $\alpha$ and $B K \beta_{1}$ protein expression as detected via western blotting. Compared with the control group, the expression level of TRPC1 protein in the AS group was increased $\left(\mathrm{P}<0.05\right.$; Fig. 4), whereas $\mathrm{BK} \alpha$ and $\mathrm{BK} \beta_{1}$ protein expression was decreased $(\mathrm{P}<0.01 ;$ Fig. 4$)$.

\section{Discussion}

AS is a form of vascular stenosis disease. Inflammatory lesions are the first signs of pathogenesis, which are characterized by the formation of lipid plaques on the arterial wall that can gradually thicken, resulting in vascular stenosis or vascular embolism caused by plaque rupture (29). Since hyperlipidemia is the most important risk factor leading to AS, simulating it in vivo is an 
A

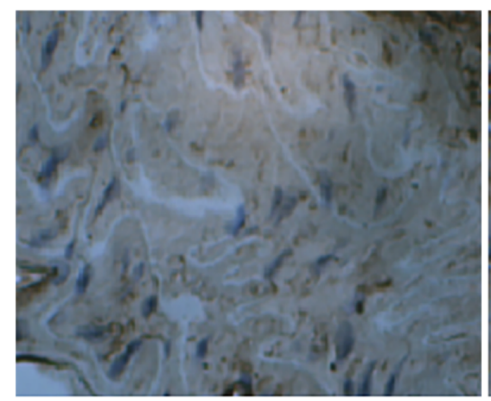

$\mathrm{D}$

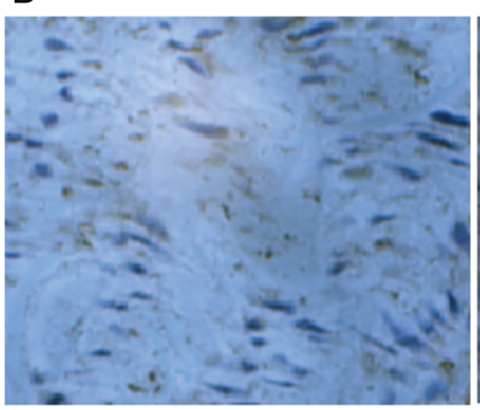

B

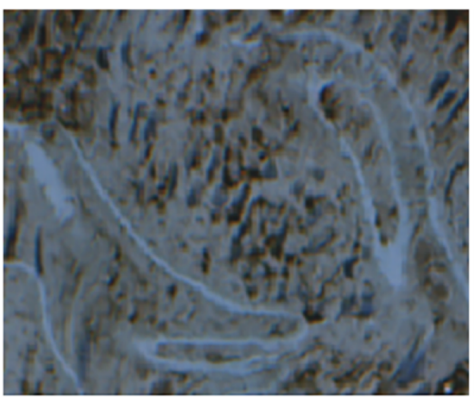

E

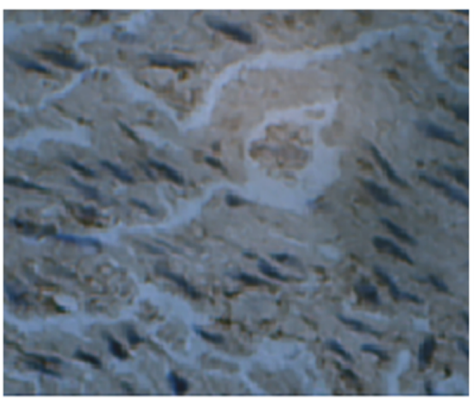

C

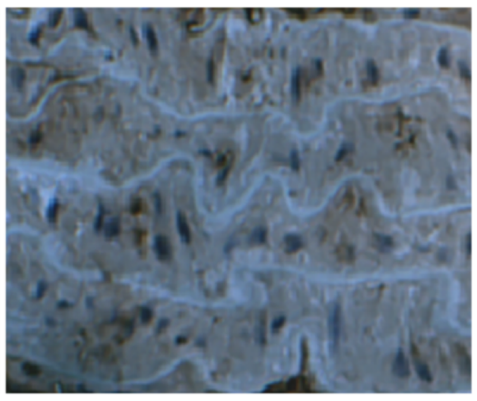

$\mathrm{F}$

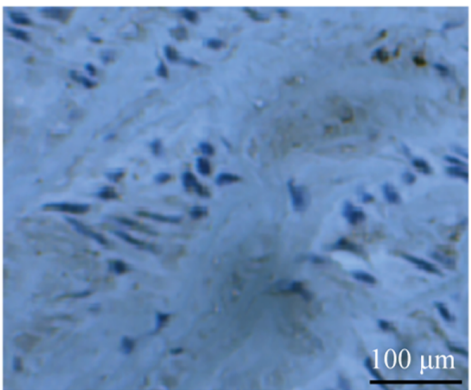

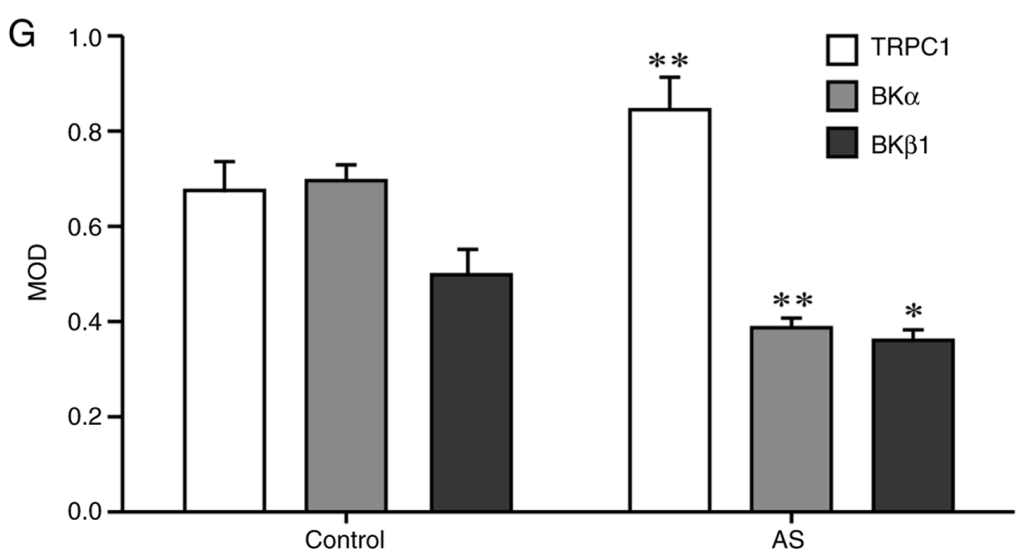

Figure 3. Immunohistochemistry for the detection of the protein expression levels in the aortic smooth muscle of the two groups. Expression levels of $(\mathrm{A}, \mathrm{B}) \mathrm{TRPC} 1,(\mathrm{C}, \mathrm{D}) \mathrm{BK} \alpha$ and $(\mathrm{E}, \mathrm{F}) \mathrm{BK} \beta_{1}$ in the aortic vascular smooth muscle of mice in each group were detected via immunohistochemistry (n=10). Panels A, C, E show results for the control group, while panels B, D and F are for the AS group. The protein expression was observed under an optical microscope (magnification, $x 400$ ). The brown-yellow shows the protein localization, while the blue area shows the nuclei. (G) The MOD of the brown-yellow area was detected via Metamorph imaging software. ${ }^{*} \mathrm{P}<0.05,{ }^{* *} \mathrm{P}<0.01$ vs. respective control group. TRPC1, transient receptor potential channel-1; BK $\alpha$, large conductance calcium-activated potassium channel $\alpha$ subunit; BK $\beta_{1}$, large conductance calcium-activated potassium channel $\beta 1$ subunit; AS, atherosclerosis; MOD, mean optical density.

ideal method to establish an AS model. Moreover, ApoE is a key regulator of plasma lipid levels, as shown by the fact that mice and humans lacking ApoE have markedly increased plasma cholesterol levels, as well as AS development (30).

When the ApoE gene is knocked out, ApoE cannot be synthesized in the body and the resultant lack of it the in blood can cause significant changes in the content of various lipoproteins. This leads to accumulation of lipids in the blood vessel walls, which is a direct consequence of the formation of lipid oxidation products, such as oxidized low density lipoprotein cholesterol (30). This can also promote phagocytosis in the blood vessel wall and lead to the formation of foamy macrophages, causing a series of inflammatory responses within the blood vessels involving of a variety of cells. The phenomenon occurs in a loop and results in the formation of vascular atherosclerotic plaques $(31,32)$.
Atherosclerotic lesions gradually penetrate the endothelium and invade the smooth muscle layers and the outer layers (27). During the progression of AS, the protein expression of various ion channels on the vascular wall cells is affected to varying degrees (33). The alterations in the ion channel proteins of the VSMCs change the internal and external physiological and biochemical processes which is crucial for the vascular smooth muscle systolic and diastolic function, thereby affecting blood flow $(33,34)$. The proteins related to the TRPC1 pathway have been detected on a variety of cell membranes, particularly on the VSMC membrane (34). $\mathrm{BK}$ is also an ion channel that is present on the cell membrane and is highly dependent on the intracellular $\mathrm{Ca}^{2+}$ concentration and mediates intracellular $\mathrm{K}^{+}$transport (35). In previous years, studies using immunofluorescence, immunoprecipitation, patch clamp tests and vascular tension measurements, 

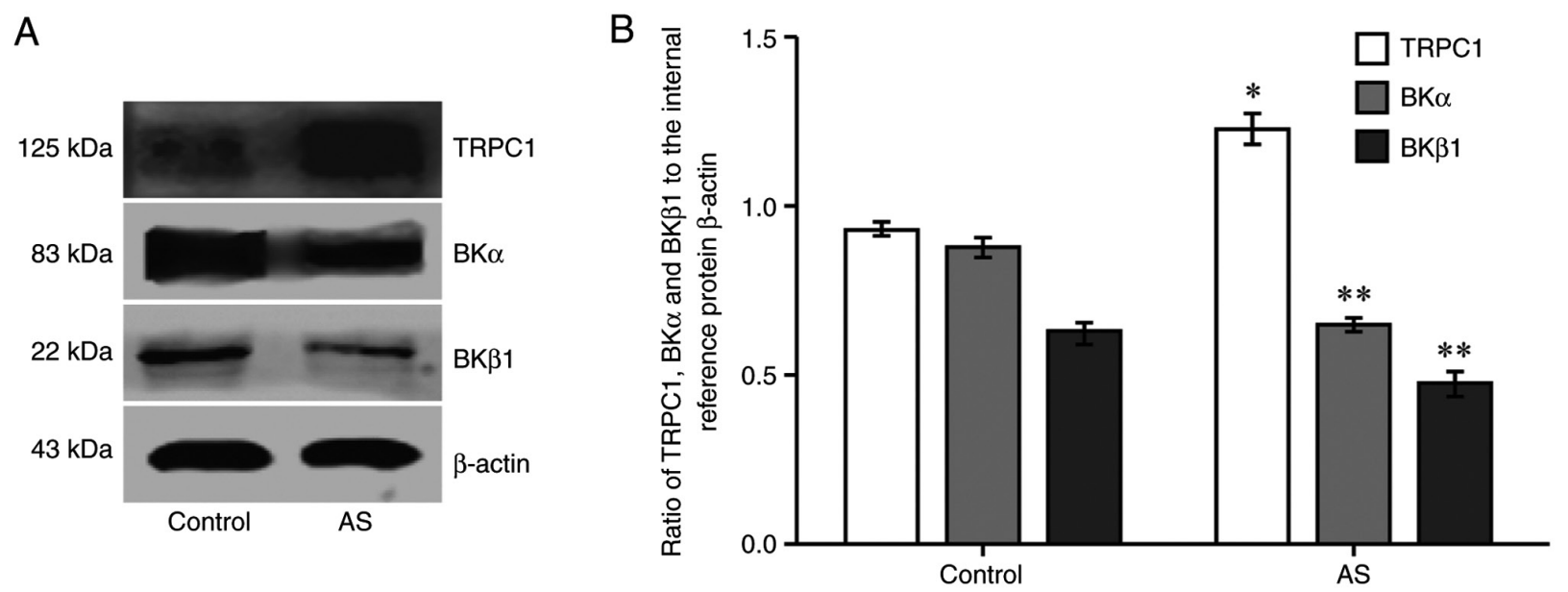

Figure 4. Western blotting was used to detect the expression of each protein in the aortic vascular smooth muscle of the two groups (n=10). (A) Western blotting bands. (B) Semi-quantification of western blotting results. " $\mathrm{P}<0.05$, ${ }^{* *} \mathrm{P}<0.01$ vs. respective control group. TRPC1, transient receptor potential channel-1; $\mathrm{BK} \alpha$, large conductance calcium-activated potassium channel $\alpha$ subunit; $\mathrm{BK} \beta_{1}$, large conductance calcium-activated potassium channel $\beta 1$ subunit; AS, atherosclerosis

as well as other research techniques, have shown that TRPC1 and BK form an ion signal complex in the thoracic aortic VSMC membrane of C57BL/6J mice $(22,31)$. The common regulation of intracellular $\mathrm{Ca}^{2+}$ concentration affects the cell surface membrane potential and, in turn, controls the vascular tension (22). In addition, studies using diabetic rats have shown significant differences in the expression of the BK protein in the coronary artery of these rats compared with that in the normal rat coronary artery (36). The present results demonstrated that there was a significant difference in the expression levels of TRPC1 and BK in atherosclerotic and normal mouse aortic smooth muscle tissue, which was consistent with these previous studies.

The present study identified that in the aortic vascular smooth muscle tissue of arterial AS mouse models and normal mice, mRNA and protein expression levels of TRPC1, BKa and $\mathrm{BK} \beta_{1}$ were different, indicating that the development of AS affects this ion channel complex, at least in the upstream transcription stage of protein synthesis from DNA to RNA. An increase in the expression of TRPC1 on the cell membrane was observed in AS, which leads to increase in the number of open channels and subsequent increase in the $\mathrm{Ca}^{2+}$ influx leading to contraction of VSMCs (34). The $\mathrm{Ca}^{2+}$ ions can also promote intracellular and extracellular matrix proliferation and increase AS vascular stenosis (37). Conversely, the expression levels of the BK proteins are decreased on the cell membrane in AS, resulting in decreased $\mathrm{K}^{+}$outflow that causes reduction in the hyperpolarization of smooth muscle cells and maintains the contraction state, further aggravating vascular stenosis (35). In addition, TRPC1 and BK are physically associated with each other in VSMCs, and $\mathrm{Ca}^{2+}$ influx via TRPC1 activates $\mathrm{BK}$, leading to membrane hyperpolarization (22), and thus, we hypothesize that an interaction of these two channels forms the TRPC1/BK signal complex. Furthermore, the dysfunction of this complex can also increase arterial atherosclerotic lesions and vascular stenosis. The TRPC1/BK signal complex may serve as a new target for the treatment of AS-related diseases. The mechanism of TRPC1/BK in the cardiovascular system is complex and has been well studied (38). However, novel strategies need to be developed using this signal complex in order to treat or prevent cardiovascular diseases in the future.

The present study has limitations. Since an animal model was used in the study, only the protein and mRNA expression levels were detected. Future studies will clarify the function of the two target proteins using inhibitors. Furthermore, immunoprecipitation tests will be conducted to help further understand the role of this complex. At present, the current experiment focused the determination of RNA and protein content. In the future, further in-depth research, such as $\mathrm{Ca}^{2+}$ measurement in VSMCs and the association of other ions with TRPC1/BK signal complex, will be examined.

In conclusion, the present study demonstrated that the mRNA and protein expression of the TRPC1/BK complex molecules is different in vascular AS compared with the control, which may provide a novel target to study vascular disease.

\section{Acknowledgements}

Not applicable.

\section{Funding}

No funding was received.

\section{Availability of data and materials}

The datasets used and/or analyzed during the current study are available from the corresponding author on reasonable request.

\section{Authors' contributions}

LFW designed this study and performed the critical revision of the manuscript. HL and QXT participated in the design of the study. DYL performed the majority of experiments and drafted the manuscript. MHX, LWT and YH performed acquisition of data. MXH, LWT, YH, HL, QXT and ZC performed data collection. BZZ, HTL, YFW and XGZ analyzed the data. ZC interpreted the research data. LFW and DYL confirmed 
the authenticity of the raw data. All authors read and approved the final manuscript.

\section{Ethics approval and consent to participate}

This study was carried out in strict accordance with the recommendations in the Guide for the Care and Use of Laboratory Animals of the National Institutes of Health. The animal use protocol has been reviewed and approved by the Institutional Animal Care and Use Committee of The 901st Hospital of Joint Logistics Support Force of PLA (approval no. 20150615).

\section{Patient consent for publication}

Not applicable.

\section{Competing interests}

The authors declare that they have no competing interests.

\section{References}

1. Falk E: Pathogenesis of atherosclerosis. J Am Coll Cardiol 47 (Suppl 8):C7-12, 2006.

2. Peng R, Ji H, Jin L, Lin S, Huang Y, Xu K, Yang Q, Sun D and $\mathrm{Wu}$ W: Macrophage-Based Therapies for Atherosclerosis Management. J Immunol Res 2020: 8131754, 2020.

3. Bai X, Wang WX, Fu RJ, Yue SJ, Gao H, Chen YY and Tang YP: Therapeutic Potential of Hydroxysafflor Yellow A on Cardio-Cerebrovascular Diseases. Front Pharmacol 11: 01265, 2020.

4. Nicholls SJ, Ballantyne CM, Barter PJ, Chapman MJ, Erbel RM, Libby P, Raichlen JS, Uno K, Borgman M, Wolski K, et al: Effect of two intensive statin regimens on progression of coronary disease. N Engl J Med 365: 2078-2087, 2011.

5. Clapham DE: TRP channels as cellular sensors. Nature 426: 517-524, 2003

6. Reyes RC, Verkhratsky A and Parpura V: TRPC1-mediated $\mathrm{Ca}^{2+}$ and $\mathrm{Na}^{+}$signalling in astroglia: Differential filtering of extracellular cations. Cell Calcium 54: 120-125, 2013.

7. Zhu Y, Ye P, Chen SL and Zhang DM: Functional regulation of large conductance $\mathrm{Ca}^{2+}$-activated $\mathrm{K}^{+}$channels in vascular diseases. Metabolism 83: 75-80, 2018.

8. Ferguson SD, Zhou S, Xiu J, Hashimoto Y, Sanai N, Kim L, Kesari S, de Groot J, Spetzler D and Heimberger AB: Ependymomas overexpress chemoresistance and DNA repair-related proteins. Oncotarget 9: 7822-7831, 2017.

9. Liu P, Verhaar AP and Peppelenbosch MP: Signaling Size: Ankyrin and SOCS Box-Containing ASB E3 Ligases in Action. Trends Biochem Sci 44: 64-74, 2019.

10. Kruglikov IL and Scherer PE: Caveolin as a Universal Target in Dermatology. Int J Mol Sci 21: 80, 2019.

11. Son A, Kang N, Oh SY, Kim KW, Muallem S, Yang YM and Shin DM: Homer2 and Homer3 modulate RANKL-induced NFATc1 signaling in osteoclastogenesis and bone metabolism. J Endocrinol 242: 241-249, 2019.

12. Ciminski K, Pulvermüller J, Adam J and Schwemmle M: Human MxA is a potent interspecies barrier for the novel bat-derived influenza A-like virus H18N11. Emerg Microbes Infect 8: 556-563, 2019.

13. Nguyen LK, Kholodenko BN and von Kriegsheim A: Rac1 and RhoA: Networks, loops and bistability. Small GTPases 9: 316-321, 2018.

14. Redondo PC, Harper AG, Salido GM, Pariente JA, Sage SO and Rosado JA: A role for SNAP-25 but not VAMPs in store-mediated $\mathrm{Ca}^{2+}$ entry in human platelets. J Physiol 558: 99-109, 2004.

15. Antigny F, Konig S, Bernheim L and Frieden M: Inositol $1,4,5$ trisphosphate receptor 1 is a key player of human myoblast differentiation. Cell Calcium 56: 513-521, 2014.

16. Dhar M, Wayman GA, Zhu M, Lambert TJ, Davare MA and Appleyard SM: Leptin-induced spine formation requires $\operatorname{TrpC}$ channels and the $\mathrm{CaM}$ kinase cascade in the hippocampus. J Neurosci 34: 10022-10033, 2014.
17. Marom M, Birnbaumer L and Atlas D: Membrane depolarization combined with Gq-activated G-protein-coupled receptors induce transient receptor potential channel 1 (TRPC1)- dependent potentiation of catecholamine release. Neuroscience 189: 132-145, 2011.

18. Tu CL, Chang W and Bikle DD: Phospholipase cgammal is required for activation of store-operated channels in human keratinocytes. J Invest Dermatol 124: 187-197, 2005.

19. Singh BB, Liu X, Tang J, Zhu MX and Ambudkar IS: Calmodulin regulates $\mathrm{Ca}(2+)$-dependent feedback inhibition of store-operated $\mathrm{Ca}(2+)$ influx by interaction with a site in the $\mathrm{C}$ terminus of TrpC1. Mol Cell 9: 739-750, 2002.

20. Selli C, Erac Y and Tosun M: Simultaneous measurement of cytosolic and mitochondrial calcium levels: Observations in TRPC1-silenced hepatocellular carcinoma cells. J Pharmacol Toxicol Methods 72: 29-34, 2015.

21. Dyrda A, Koenig S and Frieden M: STIM1 long and STIM1 gate differently TRPC1 during store-operated calcium entry. Cell Calcium 86: 102134, 2020.

22. Kwan HY, Shen B, Ma X, Kwok YC, Huang Y, Man YB, Yu S and Yao X: TRPC1 associates with BK(Ca) channel to form a signal complex in vascular smooth muscle cells. Circ Res 104: 670-678, 2009.

23. Kochukov MY, Balasubramanian A, Noel RC and Marrelli SP: Role of TRPC1 and TRPC3 channels in contraction and relaxation of mouse thoracic aorta. J Vasc Res 50: 11-20, 2013.

24. ÁvilaMedina J: CalderónSánchez E, GonzálezRodríguez P, Monje-Quiroga F, Rosado JA, Castellano A, Ordóñez A and Smani T: Orail and TRPC1 colocalize with CaV1.2 channels to form a signal complex in vascular smooth muscle cells. J Biol Chem 291: 21148-21159, 2016.

25. Nascimento Da Conceicao V, Sun Y, Zboril EK, De la Chapa JJ and Singh BB: Loss of $\mathrm{Ca}^{2+}$ entry via Orai-TRPC1 induces ER stress, initiating immune activation in macrophages. J Cell Sci 133: jcs237610, 2019. doi.org/10.1242/jcs.237610.

26. Packard RR and Libby P: Inflammation in atherosclerosis: From vascular biology to biomarker discovery and risk prediction. Clin Chem 54: 24-38, 2008.

27. Andrés-Manzano MJ, Andrés V and Dorado B: Oil Red O and Hematoxylin and Eosin Staining for Quantification of Atherosclerosis Burden in Mouse Aorta and Aortic Root. Methods Mol Biol 1339: 85-99, 2015.

28. Wang LF, Gu L, Huang MX, Zhou WB, Li H and Zhang BZ: Effects of spironolactone towards rabbit atrial remodeling with rapid pacing. Pak J Pharm Sci 29: 151-156, 2016.

29. Cochain $C$ and Zernecke A: Macrophages and immune cells in atherosclerosis: Recent advances and novel concepts. Basic Res Cardiol 110: 34, 2015.

30. Davignon J, Cohn JS, Mabile L and Bernier L: Apolipoprotein E and atherosclerosis: Insight from animal and human studies. Clin Chim Acta 286: 115-143, 1999.

31. Libby P, Lichtman AH and Hansson GK: Immune effector mechanisms implicated in atherosclerosis: From mice to humans. Immunity 38: 1092-1104, 2013.

32. Tousoulis D, Psarros C, Demosthenous M, Patel R, Antoniades $C$ and Stefanadis C: Innate and adaptive inflammation as a therapeutic target in vascular disease: The emerging role of statins. J Am Coll Cardiol 63: 2491-2502, 2014.

33. Tangvoraphonkchai K and Davenport A: Magnesium and Cardiovascular Disease. Adv Chronic Kidney Dis 25: 251-260, 2018.

34. Nesin V and Tsiokas L: TRPC1. In: Mammalian Transient Receptor Potential (TRP) Cation Channels. Handbook of Experimental Pharmacology. Nilius B and Flockerzi V (eds). Vol 222. Springer, Berlin, Heidelberg, pp15-51, 2014.

35. Latorre R, Castillo K, Carrasquel-Ursulaez W, Sepulveda RV, Gonzalez-Nilo F, Gonzalez C and Alvarez O: Molecular Determinants of BK Channel Functional Diversity and Functioning. Physiol Rev 97: 39-87, 2017.

36. Tang X, Qian LL, Wang RX, Yao Y, Dang SP, Wu Y, Wang W, Ji Y, Sun MQ, Xia DY, et al: Regulation of coronary arterial large conductance $\mathrm{Ca}^{2+}$-activated $\mathrm{K}^{+}$channel protein expression and function by n-3 polyunsaturated fatty acids in diabetic rats. J Vasc Res 54: 329-343, 2017.

37. Tykocki NR, Boerman EM and Jackson WF: Smooth muscle ion channels and regulation of vascular tone in resistance arteries and arterioles. Compr Physiol 7: 485-581, 2017.

38. Schmidt K, Dubrovska G, Nielsen G, Fesüs G, Uhrenholt TR, Hansen PB, Gudermann T, Dietrich A, Gollasch M, de Wit C, et al: Amplification of EDHF-type vasodilatations in TRPC1-deficient mice. Br J Pharmacol 161: 1722-1733, 2010.

This work is licensed under a Creative Commons Attribution-NonCommercial-NoDerivatives 4.0 International (CC BY-NC-ND 4.0) License. 